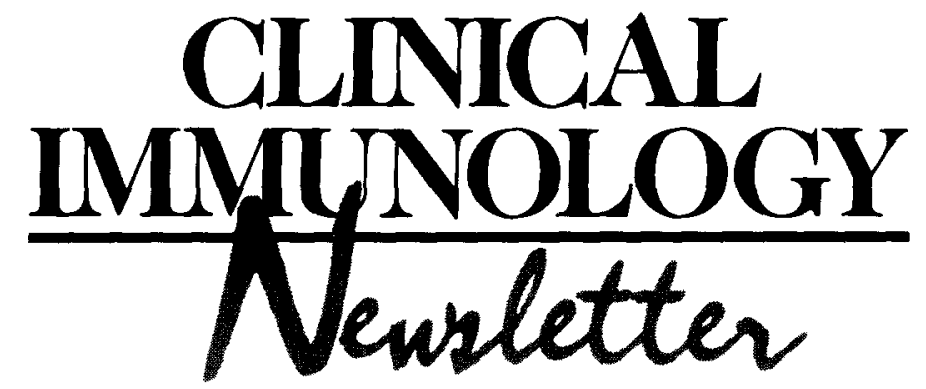

\title{
Intravenous Immune Globulin Therapy of Immune Deficiency Disorders
}

\author{
Stanley A. Schwartz \\ Department of Pediatrics, University of Michigan, Ann Arbor, Michigan
}

\section{Historical Background}

The clinical use of immune serum globulin has had a relatively long history spanning over three decades. This has been comprehensively reviewed by Dwyer. ${ }^{14}$

The principal breakthrough which resulted in the isolation of immune serum globulin or gamma globulin was the alcohol fractionation of serum proteins as developed by Cohn and his colleagues. ${ }^{12}$ This procedure allows for the selective precipitation of gamma globulins from serum by the addition of $25 \%$ cold ethanol and this component is designated Cohn fraction II. Because reconstituted Cohn fraction II caused serious systemic reactions when given intravenously, its use has been solely restricted to intramuscular administration until the recent advent of intravenous immune globulin (IVIG).

Although early use of gamma globulin included a role as an antimicrobial agent particularly during World War II when antibiotics, such as penicillin, were in very short supply, it subsequently found additional military application when given for the prophylaxis of infectious hepatitis $A$ in U.S. troops abroad. ${ }^{27}$ The definitive role of gamma globulin for antibody replacement therapy was described by Dr. Ogden Bruton, an army physician who identified the first case of primary immu- nodeficiency disease in a young boy. ${ }^{6}$ This patient was diagnosed as having hypogammaglobulinemia (which later was categorized as infantile, X-linked or Bruton's agammaglobulinemia) and was successfully treated with i.m. gamma globulin replacement therapy. Subsequently, i.m. gamma globulin became the drug of choice for the therapy of antibody deficiency syndromes, although fresh frozen plasma has also been used. ${ }^{22}$

The introduction to the U.S. of an intravenous form of immunoglobulin in 1981 permitted significant improvement in the management of immunodeficiency continued on page 146

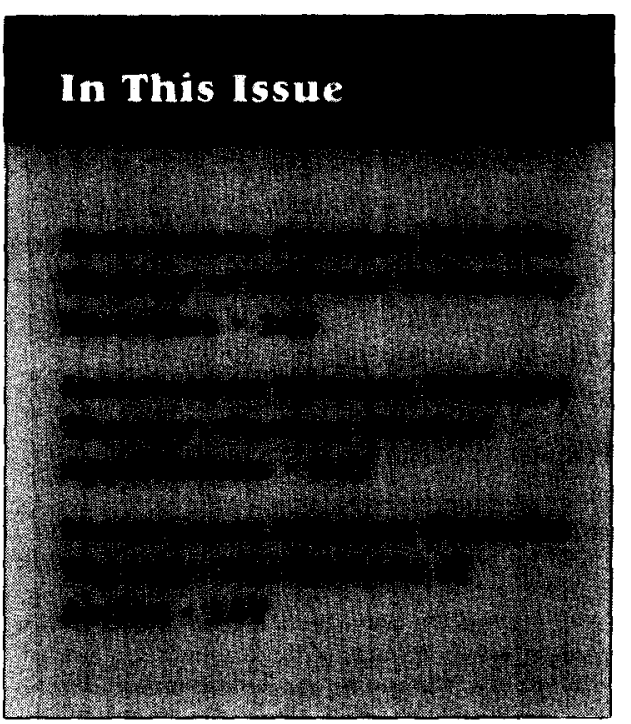

\section{Intravenous Immune Globulin Therapy: Current Clinical Applications}

\section{Renata J. M. Engler and Deborah L. Birx \\ Walter Reed Army Medical Center and Walter Reed Army Institute of Research, Washington, D.C.}

I ntravenous immune globulin (IVIG) first became available for patient use in the United States in 1981. Since that time, seven IVIG products have been approved by the FDA for clinical use. ${ }^{59,67}$ The officially licensed indications currently are replacement therapy in primary immunodeficiency disease as well as the treatment of idiopathic thrombocytopenic purpura and low-grade B-cell malignancies. The 1990 (National Institutes of Health) NIH Consensus Development Conference on Intravenous

continued on page 150

The editors wish to thank Thomas A Fleisher, M.D. for acting as Guest Editor for this issue of Clinical Immunology Newsletter. His work is greatly appreciated. 